\title{
ALTERNATIVNI MODEL INTERNE REVIZIJE U JAVNIM PREDUZEĆIMA REPUBLIKE SRBIJE
}

\author{
Daniel Pantić
}

JP Jugoimport SDPR, Beograd, Srbija
Korespondencija:

Daniel Pantić

e-mail:

danielpantic76@gmail.com

\begin{abstract}
Apstrakt:
Teorijska razmatranja i ranije sprovedene analize uputile su nas u postavljanje i predlaganje novog modela interne revizije javnih preduzeća, a sve u skladu sa zahtevima nezavisne i kompetentne interne revizije. Predloženi model može obezbediti da sistem interne revizije bude unapređen i dodatno nezavisan, objektivan i organizovan kao konsultantska aktivnost u javnim preduzećima. Kao takva može dodatno pomoći javnom preduzeću i njegovom osnivaču da ostvare generalne ciljeve putem sistematičnog i disciplinovanog pristupa procesima upravljanja rizicima, kontrolnim procesima i procesima upravljanja javnim preduzećem. Na osnovu stanja iz prakse, u model se uključuju zahtevi uočeni i usmereni ka poboljšanju pozitivnih aktivnosti i eliminisanju nedostataka postojećeg modela. Kao kritične tačke u radu interne revizije javnih preduzeća identifikovane su sledeće: problem pune nezavisnosti, praćenje adekvatne osposobljenosti i popunjenosti i pitanje profesionalne nezavisnosti kroz finansijsku nezavisnost.
\end{abstract}

Ključne reči:

interna revizija, javna preduzeća Republike Srbije, model.

Interna revizija u funkciji korporativnog upravljanja javnim preduzećima Republike Srbije predstavlja aktuelno, a čini nam se i nedovoljno objašnjeno, pitanje i nedovoljno iskorišćenu polugu u funkciji kontrole poslovanja radi ostvarenja korporativnih ciljeva (Pantić, 2016).

Sam pojam interne finansijske kontrole u javnom sektoru (PIFC) obuhvata: finansijsko upravljanje i kontrolu kod korisnika javnih sredstava, internu reviziju kod korisnika javnih sredstava i harmonizaciju i koordinaciju finansijskog upravljanja i kontrole i interne revizije koju obavlja Ministarstvo finansija - Centralna jedinica za harmonizaciju (Zakon o budžetskom sistemu, 2011). Sa aspekta javnog preduzeća, postojeći model PIFC može se prikazati na slici 1.

Uvažavajući teorijske koncepte i uočene nedostatke postojećeg modela interne revizije u javnim preduzećima, predložen je novi model interne revizije u javnim preduzećima, baziran na aspektu nezavisnosti, adekvatnoj osposobljenosti i popunjenosti, kao i na finansijskoj nezavisnosti.

Model predviđa da se pod Centralnom jedinicom za harmonizaciju - Ministarstvo finansija, formira Jedinica za internu reviziju javnih preduzeća Republike Srbije. U svom sastavu ona bi imala upravni i operativni deo. Upravni deo Jedinice bavio bi se poslovima koordinacije i upravljanja; planiranjem i izveštavanjem; kontrolom i administrativnom podrškom. U operativnom delu Jedinice, nalazili bi se timovi, popunjeni adekvatno osposobljenim kadrom, od kojih bi svaki tim bio zadužen za jedno javno preduzeće. Ovakvo ustrojstvo interne revizije dalo bi joj nezavisnost, pružilo podlogu za objektivnost i ustanovilo organizacionu nezavisnost. Pri tom, upravni deo Jedinice bio bi organizaciono i fizički izdvojen iz javnih preduzeća, a timovi bi bili locirani u samim javnim preduzećima. 


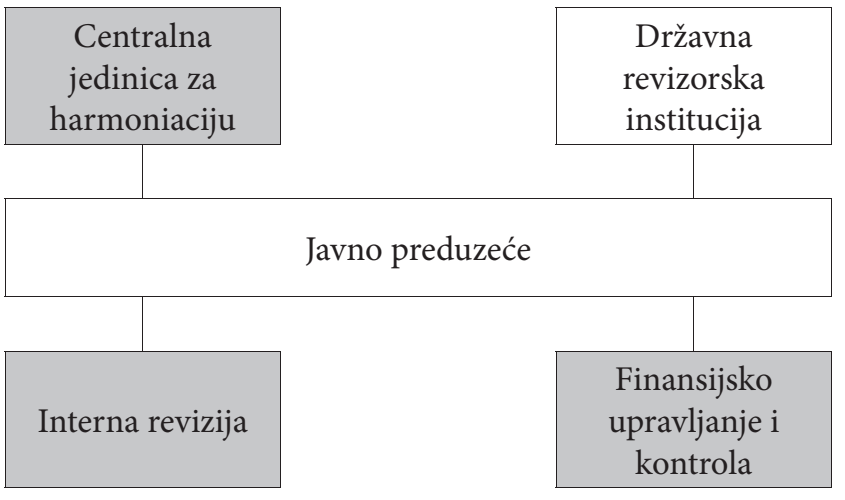

Slika 1: Postojeći model interne finansijske kontrole u javnom sektoru

Izvor: Samostalan rad autora.

Predloženim modelom nijedna od komponenti interne finansijske kontrole u javnom sektoru, posebno u delu koji se odnosi na javna preduzeća, nije izostavljena. Samo je izvršeno njeno drugačije organizovanje, a u cilju obezbeđenja pune nezavisnosti, osposobljenosti, popunjenosti i finansijske nezavisnosti interne revizije.

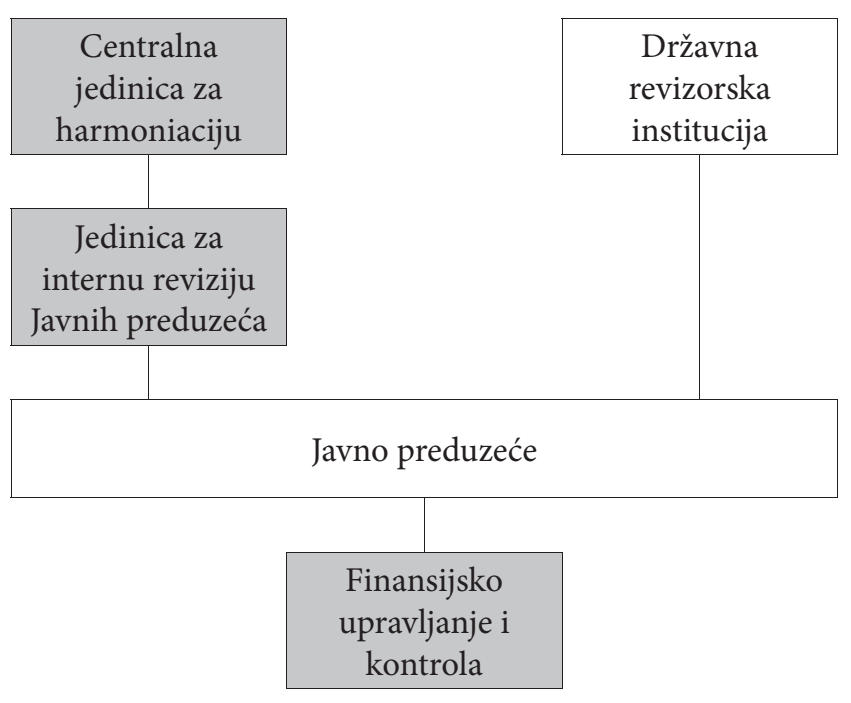

Slika 2: Predloženi model interne finansijske kontrole u javnom sektoru

Izvor: Samostalan rad autora

Predloženi model alternativno može biti uspostavljen i na način da Jedinica za internu reviziju javnih preduzeća bude samostalna organizaciona celina u nekom od nadležnih ministarstava. U tom slučaju, Centralna jedinica za harmonizaciju bi zadržala trenutne nadležnosti koje je postojeće zakonodavstvo pred nju postavilo.

\section{DEFINICIJA MODELA INTERNE REVIZIJE U JAVNIM PREDUZEĆIMA SA ASPEKTA NEZAVISNOSTI}

Institut internih revizora (IIA) definiše i tumači standarde koji treba da se primenjuju u organizaciji i pri radu interne revizije u istoj, i koji su samim tim primenjivi i sa aspekta javnih preduzeća. Između ostalog, a kao ključni, definisani su sledeći standardi:

- 1100 - Nezavisnost i objektivnost i

- 1110 - Organizaciona nezavisnost (IIA, 2011).

Nezavisnost i objektivnost - jer interna revizija podrazumeva da mora da bude nezavisna, a interni revizori objektivni u obavljanju svojih poslova. Pretnja nezavisnosti mora biti kontrolisana na način da nisu učinjeni nikakvi ustupci kada je u pitanju kvalitet rada interne revizije. Objektivnost zahteva da interni revizori ne podređuju svoje mišljenje o pitanjima revizije mišljenju drugih.

Organizaciona nezavisnost - po proceduri, izvršni rukovodilac revizije mora da izveštava nivo rukovodstva u organizaciji koji internoj reviziji omogućava da ispuni svoje obaveze. Funkcija interne revizije mora biti slobodna od uticaja drugih kod određivanja delokruga revizije, izvršenja posla i saopštavanja rezultata. Organizaciona nezavisnost, takođe, onemogućuje da organizacija koja je predmet revizije (u našem slučaju javno preduzeće) vrši uticaj na unutrašnju strukturu i na profesionalnu karijeru revizora koji su zaposleni u internoj reviziji. Obezbeđena organizaciona nezavisnost je preduslov postojanja funkcionalne nezavisnosti.

Priroda interne revizije, i njena uloga pružanja nepristrasnih i tačnih informacija o korišćenju javnih resursa zahteva da se aktivnost interne revizije obavlja bez ograničenja - bez mešanja ili pritisaka iz organizacije koja je predmet revizije, ili iz oblasti koja je predmet revizije (INTOSAI General secretariat, 2006). Sagledavanjem dva ključna standarda Instituta internih revizora, a potvrđeno iskustveno i kroz prethodno obavljene analize, proizilazi model čija primena obezbeđuje nezavisnost.

Naime, radi se o formiranju novog organizacionog dela koji se zove Jedinica za internu reviziju javnih preduzeća (u daljem tekstu Jedinica). Jedinica predstavlja nezavisnu organizacionu celinu, organizovanu pod Centralnom jedinicom za harmonizaciju, zadužena za poslove interne revizije Javnih preduzeća ili, u drugoj opciji, izvan Centralne jedinice za harmonizaciju ili kao posebna Agencija interne revizije javnih preduzeća u okviru Ministarstva finansija. Jedinica je organizovana na način da obuhvata dve interne, funkcionalno povezane celine, a to su:

- Upravni deo jedinice za internu reviziju javnih preduzeća, u funkciji upravljanja i kontrole, i

- Timovi Jedinice za funkciju interne revizije u javnom preduzeću, u funkciji planiranja aktivnosti, sprovođenja revizija i izveštavanje po modelu. 
Pod Centralnom jedinicom za harmonizaciju, bila bi formirana Jedinica za internu reviziju javnih preduzeća Republike Srbije. Jedinica bi imala upravni i operativni deo. Upravni deo Jedinice vodio bi direktor, i u sklopu upravnog dela organizaciono bili bi formirani sektori za:

- Koordinaciju i upravljanje,

- Planiranje i izveštavanje,

- Kontrolu, i

- Administrativnu podršku.

Organizacija upravnog dela treba da obezbedi koordinaciju i upravljanje, planiranje i izveštavanje, kontrolu i administrativnu podršku timovima interne revizije. Ovim modelom se ne narušava sistem postojeće interne kontrole u javnom sektoru, već se isti unapređuje i ojačava.

Operativni deo se sastoji od timova dovoljno popunjenih osposobljenim kadrom, adekvatnim i kompetentnim, od kojih bi svaki tim bio zadužen za jedno javno preduzeće. Timom rukovodi interni revizor. Timovi u svom sastavu imaju sledeće grupe:

- Za reviziju poslovanja u domenu pretežne delatnosti javnog preduzeća (distribucija struje, trgovina oružjem, distribucija gasa, i sl.);

- Za reviziju univerzalnih aktivnosti poslovanja (finansije, pravni poslovi, javne nabavke, i sl.);

- Za reviziju IT aktivnosti javnih preduzeća.

Upravljanje Jedinicom je povereno Centralnoj jedinici za harmonizaciju. Postupak kontrole Jedinice je dvostepen - sa jedne strane po službenoj dužnosti Jedinica je kontrolisana od strane Centralne jedinice za harmonizaciju, a sa druge strane je kontrolisana od strane Državne revizorske institucije.

Organizacija aktivnosti interne revizije postavljena je na način koji obezbeđuje saradnju sa rukovodstvom i zaposlenima subjekta revizije, pri čemu interni revizori imaju slobodan, neograničen pristup svim funkcijama, evidencijama, imovini, dokumentaciji i zaposlenima - uključujući i one zadužene za upravljanje. Prema modelu interne revizije Jedinice, data je šema organizacije aktivnosti interne revizije na prethodnoj slici.

Proces planiranja aktivnosti timova, odnosno planiranje revizija, radi se u skladu sa procenom rizika, a rizici su ocenjivani od strane timova, a u saradnji sa rukovodstvima i nadležnim organima javnih preduzeća. Konačnu reč o predloženim planovima (planovima predloženim od strane timova), daje Centralna jedinica za harmonizaciju. Planovi postaju sastavni deo programa poslovanja javnih preduzeća, a programe poslovanja usvaja Vlada Republike Srbije. Ovo je potpun i kontrolisan postupak planiranja koji obuhvata praćenje ostvarenja plana, te kao takav, dobija posebni značaj i kod rukovodilaca i kod nadležnih organa javnih preduzeća. Istovremeno, planovi predviđaju i obavezan deo vremena za vanredne revizije na inicijativu internog revizora i revizije na predlog rukovodstva javnih preduzeća.
Poštujući usvojene planove revizije, nakon sprovedenih revizija u skladu sa definisanom metodologijom, timovi sačinjavaju nacrte izveštaja. Nacrti su usaglašeni sa revidiranim delovima javnih preduzeća, a ako pretpostavimo da usaglašavanje ne bi bilo moguće, tada se predviđa da interni revizor tima ima diskreciono pravo da da primedbe i preporuke ili da ih izostavi ukoliko stekne uverenje da preporuke nisu na mestu.

Izveštaje o izvršenim revizijama, zajedno sa preporukama, timovi dostavljaju i Centralnoj jedinici za harmonizaciju i nadležnim organima javnog preduzeća (nadzorni odbor, direktor, komisija za reviziju, revidirani rukovodioci). Potom, tromesečno direktor i revidirani rukovodioci, posredstvom tima za internu reviziju, dostavljaju izveštaj o primeni preporuka Centralnoj jedinici za harmonizaciju. Izveštavanje kao proces, mora omogućiti internoj reviziji da ispuni svoje ciljeve.

U svom radu, odnosno u postupku izvršenja revizije, timovi poštuju propisane i prihvaćene smernice, i standarde interne revizije (UIRS, 2015).

\section{DEFINISANJE MODELA INTERNE REVIZIJE U JAVNIM PREDUZEĆIMA SA ASPEKTA ADEKVATNE OSPOSOBLJENOSTI I POPUNJENOSTI}

Postavka modela sa aspekta adekvatne osposobljenosti i popunjenosti, zasnovana je na primeni Standarda 2030 Upravljanje resursima, definisanog od strane Instituta internih revizora. On navodi da Interna revizija mora biti bazirana na preduslovu da su njeni resursi odgovarajući, dovoljni i da se efikasno i efektivno koriste na ostvarenju odobrenog plana (IIA, 2011).

Pod terminom odgovarajući smatra se skup znanja, veština i drugih sposobnosti neophodnih za realizaciju plana (ili drugačije rečeno osposobljenost).

Termin dovoljno odnosi se na kvantitet resursa neophodnih za realizaciju plana.

Termin "odgovarajući" odnosi se na osposobljenost interne revizije i internih revizora (znanjem, veštinama i sposobnostima), a termin "dovoljno" se odnosi na popunjenost interne revizije (ljudima, opremom, prostorom, vremenom i novcem).

U formiranoj Jedinici se podrazumeva da su zadovoljeni odgovarajući uslovi i sa aspekta dovoljnosti ljudskih resursa. Resursi se efektivno koriste onda kada se koriste na način kojim se optimizuje ostvarenje odobrenog plana. Samo odgovarajuća i dovoljna interna revizija može obavljati različite poslove. Posedovanje određenih sposobnosti, ključno je za obavljanje određenih zadataka (Bailey, 2010).

Osposobljenost, na direktan način utiče na kvalitet aktivnosti revizije, a samim tim i na predviđene aktivnosti Jedinice za internu reviziju javnih preduzeća i njenih timova. Zbog specifičnosti dodeljene uloge, pored znanja i veština uobičajenih 
za rad revizora, interni revizori zaposleni u Jedinici, moraju imati i specifična znanja vezana za rad javnih preduzeća.

Znanja i sposobnosti zaposleni u Jedinici stiču redovnim školovanjem, sticanjem profesionalnih iskustava - radom, uz kontinuirano usavršavanje organizovano od strane Centralne jedinice za harmonizaciju, i uz lično usavršavanje. Adekvatnost popunjenosti se, pre svega, odnosi na popunjenost brojem ljudi i popunjenost odgovarajućim materijalnim sredstvima.

Materijalna opremljenost, prema ovom modelu, podrazumeva obezbeđivanje adekvatnog prostora za upravni deo Jedinice. Takođe, za njihov rad neophodno je obezbediti računare, telefone i potrošni materijal za zaposlene u upravnom delu.

Interni revizori primenjuju znanja, veštine i iskustvo potrebno za obavljanje usluga unutrašnje revizije (IIA, 2009). Kompetentnost internih revizora, definisana u Etičkom kodeksu, podrazumeva da se interni revizori angažuju samo u onim uslugama za koje imaju potrebna znanja, veštine i iskustvo. Oni treba da obavljaju usluge interne revizije u skladu sa Međunarodnim standardima za profesionalnu praksu interne revizije i dužni su da stalno poboljšavaju svoju stručnost, efikasnosti kvalitet svojih usluga (IIA, 2009). Posedovanje određenih sposobnosti, ključno je za obavljanje određenih zadataka.

Ovaj model omogućuje dovoljnost, odnosno popunjenost timova interne revizije adekvatnim brojem ljudi. Predmet posebne analize (koja ovde nije posebno objašnjena) je odnos zaposlenih u reviziji i ukupnog broja zaposlenih u javnim preduzećima. Interna revizija u organizaciji ima do $1 \%$ zaposlenih, ne preko toga. Pojedine studije, koje su bile dostupne, predlažu da u odnosu na broj zaposlenih, broj ljudi u internoj reviziji čini 0,223\% (Urton et al., 2010).

Kombinacijom ustaljenog mišljenja da interna revizija ima $1 \%$ od broja zaposlenih i zaključaka pomenutih studija po kome se broj zaposlenih kreće na nivou od 0,223\% doveli su do predloga prema kome timovi interne revizije javnih preduzeća, u zavisnosti od ukupnog broja zaposlenih u javnom preduzeću imaju:

1. Javna preuzeća do 1.000 zaposlenih - $1 \%$ od broja zaposlenih, ali ne manje od 3 niti više od 5 zaposlenih $u$ timu,

2. Javna preuzeća od 1.001 do 4.000 zaposlenih - 0,612\% od broja zaposlenih (procenat je dobijen kao geometrijska sredina $1 \%$ i 0,223\%) u timu i

3. Javna preduzeća sa više od 4.000 zaposlenih - 0,223\% od broja zaposlenih u timu.

\section{DEFINISANJE MODELA INTERNE REVIZIJE U JAVNIM PREDUZEĆIMA SA ASPEKTA FINANSIJSKE NEZAVISNOSTI}

Kontrola ličnih primanja predstavlja jednu od glavnih poluga uticaja koju rukovodstva javnih preduzeća imaju u pogledu svojih zaposlenih. U postojećem modelu u kome fi- gurira interna revizija, direktori javnih preduzeća direktno kontrolišu i lična primanja revizora.

Prema INTOSAI deklaraciji, važećoj do 1977. godine, revizor mora da poseduje organizacionu, funkcionalnu i finansijsku nezavisnost u odnosu na revidirane subjekte (Griter, 2011). Cilj svih oblika nezavisnosti je da se spreči svaki pokušaj kojim rukovodstvo javnih preduzeća može manipulisati radom interne revizije. Takođe, treba da se osigura nezavisnost interne revizije, stvaranjem adekvatne zakonske zaštite.

Javna preduzeća, u skladu sa redefinisanim zakonskim okvirom, mesečno bi izdvajala i uplaćivala Jedinici, deo sredstava za isplatu zarada zaposlenih u Upravnom delu jedinice, i za zarade zaposlenih u timovima. Pored izdvajanja za zarade zaposlenih u Jedinici, javna preduzeća bila bi u obavezi da mesečno izdvajaju i sredstva za operativan rad kako zaposlenih u timovima, tako i zaposlenih u upravnom delu Jedinice. Pored izdvajanja, koja predstavljaju troškove, javna preduzeća bi inicijalno izdvojila i sredstva za opremanje dodeljenog poslovnog prostora upravnom delu Jedinice.

Model pruža finansijsku nezavisnost internih revizora u javnim preduzećima i pokriće troškova za rad Jedinice za internu reviziju javnih preduzeća u celosti (upravni deo i timovi). Njime se obezbeđuje finansijska nezavisnost kod nadoknade zarada zaposlenih u Jedinici (upravni deo i interni revizori u timovima javnih preduzeća) i finansijska nezavisnost za pokriće troškova funkcionisanja, kako za upravni deo tako i za interne revizore u Timovima javnih preduzeća.

Rešavanjem pitanja zarada zaposlenih u Jedinici za internu reviziju javnih preduzeća, i rešavanjem troškova njihovog operativnog poslovanja, stvaraju se uslovi za postojanje njihove finansijske nezavisnosti. Zakonskom regulativom, moguće je stvoriti okvir koji obezbeđuje nesmetano i pravovremeno obezbeđivanje sredstava, za nesmetano funkcionisanje Jedinice.

\section{ZAKLJUČAK}

Postojeći model koji se primenjuje kada je u pitanju interna revizija javnih preduzeća Republike Srbije, baziran je na stvorenom zakonskom i regulatornom okviru. Kao takav, on predstavlja prednost $\mathrm{u}$ radu interne revizije javnih preduzeća. To ni u kom slučaju ne znači da se isti u narednom periodu ne treba dorađivati i usavršavati. Dorada postojećeg regulatornog okvira mora biti kontinuirana aktivnost nadležnih državnih organa, a kako bi se interna revizija i njen rad unapredili.

Predloženi model predviđa da se pod Centralnom jedinicom za harmonizaciju - Ministarstvo finansija, formira Jedinica za internu reviziju Javnih preduzeća Republike Srbije, čime se dodatno obezbeđuje nezavisnost u njenom radu. Radi ispunjenja zadataka, ovako formirana interna revizija mora biti osposobljena (njeni zaposleni moraju imati skup dovoljnih znanja, veština i drugih sposobnosti neophodnih za rad), 
i kvantitativno popunjena (ljudstvom i neophodnim sredstvima za rad). Kada se govorilo o osposobljenosti zaposlenih u ovakvoj internoj reviziji, akcenat je stavljen na: redovno školovanje, profesionalno iskustvo; usavršavanje organizovano od strane Centralne jedinice za harmonizaciju i lično usavršavanje. Pri razmatranju broja zaposlenih u timovima interne revizije javnih preduzeća, uvažena su uobičajena mišljenja, inostrana istraživanja i potrebe datog modela. Kod tumačenja finansijske nezavisnosti i pokrića troškova, modelom su pokrivena dva ključna pitanja, koja se odnose na: nadoknade zarada zaposlenih u Jedinici (upravni deo i interni revizori u timovima javnih preduzeća) i pokriće troškova funkcionisanja (kako za upravni deo tako i za interne revizore u timovima javnih preduzeća). Sredstva za rad (zarade i pokriće troškova poslovanja) pokrivaju javna preduzeća mesečnom isplatom.

Novopredloženi model interne revizije u javnim preduzećima, sa aspekta nezavisnosti, popunjenosti i osposobljenosti, kao i finansijske nezavisnosti, može znatno unaprediti postojeći nivo svih navedenih komponenti. Funkcija interne revizije time bi dobila na dodatnom značaju, a permanentni monitoring u radu javnih preduzeća doveo bi do unapređenja ekonomičnosti i efikasnosti njihovog poslovanja.

\section{LITERATURA}

Bailey, J.A. (2010). Core Competencies for Today's Internal Auditor. Altamonte Springs: IIA Research Fondation.

Griter, K. (2011). Uslovi za uspešnu reviziju: Izbegavanje preklapanja zaduženja između kontrolnih organa. Pristupljeno 10. januara 2016. www.antikorupcija-savet.gov.rs

INTOSAI General Secretariat (2006). Internal Audit Independence in the Public Sector. Pristupljeno 11. novembra 2015. www.intosai.org

Pantić, D. (2016). Funkcija interne revizije u korporativnom upravljanju javnim preduzećima Republike Srbije - doktorska disertacija. Beograd: Beogradska bankarska akademija.

Službeni glasnik Republike Srbije. (2011). Zakon o budžetskom sistemu. Službeni glasnik republike Srbije, br. 54/2009, 73/2010, 101/2010, 101/2011

The Institute of Internal Auditors. (2009). Code of Etics. Pristupljeno 10. marta 2016. https://na.theiia.org

The Institute of Internal Auditors. (2011). Standardi IIA. Pristupljeno 10. marta 2016. https://global.theiia.org/translations/ PublicDocuments/Standards_2011_Bosnian.pdf

Udruženje internih revizora Srbije. (2015). Standardi IIA. Pristupljeno 15. marta 2015. www.uirs.rs

UIRS. (2015). Zbirka smernica interne revizije: MOPP, Stanovišta, Modeli. Beograd: Udruženje internih revizora Srbije.

Urton, L.A, Christ, M., Johnstone, K., \& Rittenberg, L. (2010). Effective Sizing of Internal Audit departments. Altamonte Springs: IIA Research Fondation.

\section{ALTERNATIVE MODEL OF INTERNAL AUDIT IN PUBLIC ENTERPRISES OF THE REPUBLIC OF SERBIA}

\section{Abstract:}

Theoretical considerations and previously performed analyses have indicated that we should establish and propose a new model of internal audit of public enterprises, in accordance with the requirements of an independent and competent internal audit. The proposed model can provide the improvement of internal audit system and make it more independent, objective and consultative activity in public enterprises. As such, it can further help public enterprise and its founder to achieve general goals through a systematic and disciplined approach to risk management processes, control processes and those of public enterprise management. Based on the current practice, this model includes the requirements which are recognised and directed to improve positive activities and eliminate the weaknesses of the existing model. The following critical issues have been identified in the process of internal audit of public enterprises: the issue of complete independence, adequate competence and availability monitoring, as well as the issue of professional independence through financial independence.

\section{Keywords:}

internal audit, Public enterprises of the Republic of Serbia,

model. 